\title{
Esporte, futurismo e modernidade
}

Victor Andrade de Melo*

\begin{abstract}
Resumo:
Este estudo tem por objetivo discutir as relações entre o esporte e o Futurismo, um dos mais ruidosos, influentes e polêmicos movimentos da vanguarda artística européia no pré Primeira Grande Guerra. Cremos que tal discussão pode nos permitir melhor desvendar os papéis ocupados por essas importantes práticas sociais (esporte e arte), a partir de seus diálogos, na construção do ideário e do imaginário da modernidade nas décadas iniciais do século XX. Para alcance do objetivo, dialogamos com as idéias de Peter Burke (2004) sobre a possibilidade de construir uma "história cultural da imagem" ou uma "antropologia histórica da imagem". Optamos ainda por conceder ênfase à análise de obras e manifestos da primeira fase do Futurismo. Esperamos, assim, dar prosseguimento a nossos esforços de promoção de uma "arqueologia social" do fenômeno esportivo, desvendando sua presença nas mais diferentes redes e teias sociais.
\end{abstract}

Palavras-chave: esporte; futurismo; modernidade.

\section{Introdução}

\begin{abstract}
A arte e a literatura são para o esporte uma sociologia indireta, uma psicanálise, um testemunho .... A investigação da presença do esporte na arte nos interessa na medida em que nos esclarece sobre a identidade do esporte e sobre o papel do imaginário na constituição das relações esportivas ... . O esporte não é simplesmente o indício de uma sociedade lúdica (ignorada ou tolerada), mas a sociedade lúdica percebida e descrita pelos meios da arte, em um quadro de expressão de sua valorização pela sociedade global. (Jeu, 1992, p. 21)
\end{abstract}

Em estudos anteriores já se discutiram os férteis diálogos e relações estabelecidas entre o esporte e a arte, no âmbito do teatro (Soares, 1979), do cinema (Marañón, 2005; Melo, 2006), da música (Branco, 2006) e das artes plásticas (González, 2003; Huitorel, 2005; Melo, 2006b), entre outros. Os relacionamentos entre as duas manifestações culturais já foram inclusive tema de reflexão de importantes filósofos, como Gordon Graham (1997), Wolgang Welsch (2001) e Hans Gumbrecht (2006).

Tendo em vista uma investigação histórica, há duas importantes potencialidades quando abordamos a relação entre esporte e arte. Uma delas é investigar os diálogos inter-semióticos e possíveis "coincidências" entre os seus percursos: na verdade, indicadores de um relacionamento mais profundo no âmbito de um determinado 
contexto sócio-cultural. Nesse sentido, é possível identificar como estiveram imbricados na consolidação de um imaginário comum.

A segunda potencialidade é, entendendo as obras de arte como possíveis fontes (ou "indícios", como prefere Burke, 2004), discutir as representações de esporte, buscando desvendar o espaço e o papel que a prática esportiva ocupou em determinado quadro social. Para tal, parece fértil dialogar com as reflexões de Peter Burke sobre a possibilidade de construir uma "história cultural da imagem" ou uma "antropologia histórica da imagem" que "pretende reconstruir as regras ou convenções, conscientes ou inconscientes, que regem a percepção e a interpretação de imagens numa determinada cultura" (2004, p. 227).

Quanto à possibilidade de usar imagens como fontes/indícios, afirma o autor:

Em outras palavras, os testemunhos sobre o passado oferecidos pelas imagens são de valor real, suplementando, bem como apoiando, as evidências dos documentos escritos. É verdade que, especialmente no caso da história dos acontecimentos, elas freqüentemente dizem aos historiadores que conhecem os documentos algo que essencialmente eles já sabiam. Entretanto, mesmo nestes casos, as imagens têm algo a acrescentar. Elas oferecem acesso a aspectos do passado que outras fontes não alcançam. (ibidem, p. 233)

Neste estudo, trabalharemos com um movimento da vanguarda artística européia. Sobre a arte moderna, afirma Briony Fer:

... a pintura moderna foi um produto de uma cultura moderna, mas não o único produto; foi uma forma de produção entre muitas outras formas complexas de representação visual, incluindo a pintura acadêmica, a ilustração popular, a fotografia e assim por diante. Formas diferentes de representação são produzidas na mesma cultura e é possível demonstrar que essas formas interagem, têm convenções e suposições em comum sobre o mundo e também contestam o que é significativo nessa cultura (1998, p.13).

Melo (2006a, 2006b), dialogando com essa idéia de Fer, buscou demonstrar que o esporte esteve articulado com o cinema e com as artes plásticas (notadamente com as obras do impressionismo) na construção do ideário da modernidade nos anos finais do século XIX, momentos primordiais da constituição do que chamamos de sociedade do espetáculo (Debord, 1997). A prática esportiva estava diretamente articulada com os sentidos e significados de um novo modus vivendi que incluía o desafio, o movimento, a exposição corporal, a velocidade, a busca do prazer e da excitação, a crença na ciência e no progresso, a idéia de multidão, a formação de uma cultura urbana que também dialoga com o gosto das camadas médias e populares. 
Como esse relacionamento entre esporte e arte terá ocorrido no âmbito do Futurismo, um dos mais ruidosos e polêmicos movimentos artísticos do pré-1 ${ }^{a}$ Grande Guerra? Este estudo, tendo em vista as duas potencialidades anteriormente apresentadas, tem por objetivo discutir as relações entre o esporte e o Futurismo. Cremos que tal discussão pode nos permitir melhor desvendar os papéis ocupados por essas importantes práticas sociais (esporte e arte), a partir de seus diálogos, na construção do ideário e do imaginário da modernidade nas décadas iniciais do século XX. Esperamos, assim, dar prosseguimento a nossos esforços de promoção de uma "arqueologia social" do fenômeno esportivo, desvendando sua presença nas mais diferentes redes e teias sociais.

Vale destacar que neste estudo vamos nos debruçar mais profundamente sobre a primeira fase do movimento, que vai de 1909 até a $1^{\text {a }}$ Grande Guerra, ainda que façamos várias referências a momentos posteriores. Fizemos essa opção na esteira do que consideram alguns autores como Micheli: "de fato, com a eclosão da guerra, a aventura figurativa do futurismo podia ser considerada concluída. O que veio depois não teve nem a importância, nem a força do primeiro futurismo" (2004, p. 211).

Gramsci também percebera tal mudança à época. Em carta enviada a Trotski, comenta: "O movimento futurista na Itália perdeu completamente seus traços característicos depois da guerra ... . Os principais porta-vozes do futurismo de antes da guerra tornaram-se fascistas" (in Trotski, 2007, p. 131) ${ }^{1}$. Não queremos aqui debater a tese de que o Futurismo foi o movimento "oficial" do fascismo, muito aceita a partir das posições de Walter Benjamin, mas já matizada por estudiosos contemporâneos (como Micheli, 2004, e Tisdall e Bozzolla, 2003), nem tampouco negar tal relacionamento; apenas estamos afirmando que suas duas fases possuem diferenças marcantes, nos parecendo mais interessante para o intuito de nossa pesquisa o primeiro instante, por sua originalidade e influência.

Vejamos, então, se é possível estabelecer relações entre o Futurismo e o esporte, uma prática social cujas origens, no seu sentido moderno, podem ser encontradas no século XIX (Bourdieu, 1983, Corbin, 2001), e que nos anos iniciais do século XX já gozava de grande popularidade, penetrabilidade e espaço na sociedade.

\section{O Futurismo italiano e o esporte}

O ano de 1909 é considerado de fundação do Futurismo. Na ocasião, Filippo Marinetti, líder e um dos nomes-chave na condução do movimento, publicou, no jornal 
francês Le Figaro, o primeiro manifesto do Futurismo, com uma série de provocações e propostas para a arte. Como comenta Umberto Boccioni: "De un solo golpe, un grupo de artistas geniales, animosos, enérgicos, enemigos de los libros, ha situado a Italia en la vanguardia de las investigaciones plásticas” (2004, p. 11).

Um dos aspectos mais interessantes do movimento futurista é o fato de não resumir suas propostas à arte, nem tampouco às artes plásticas, englobando ainda a música, o cinema, a dança. O Futurismo possuía um programa político explícito, espraiando suas proposições por todos os campos da vida. As palavras de Sylvia Martin nos ajudam a entender com maior precisão a sua amplitude:

Su objetivo común era la renovación de la vida social en todos sus ámbitos, tanto artísticos como sociales; los nuevos logros técnicos y los últimos descubrimientos científicos iban a representar el punto de partida y el módulo de sus ideas. De ahí que el futurismo no constituya una vanguardia que, como el cubismo por ejemplo, trabaja exclusivamente en innovaciones estéticas formales, sino que es más bien un movimiento vital. (2005, p. 6)

Dialogando com o contexto social europeu, expressão de seu momento histórico, notadamente com a situação peculiar da Itália:

O futurismo reflete na arte o período histórico que começou em meados dos anos 1890 e acabou na Primeira Guerra Mundial. A sociedade capitalista conheceu dois decênios de ascensão econômica sem precedente - que derrubou velhos conceitos de riqueza e poder, elaborou novos padrões, novos critérios do possível e do impossível, e impulsionou o povo a novos atos ousados. (Trotski, 2007, p. 107)

Os futuristas foram muito influenciados pelas teorias filosóficas acerca das percepções sensórias diferenciadas estabelecidas pelas novas organizações urbanas e do mundo do trabalho industrial. Posicionando-se de encontro à idéia de valorização da tradição, os artistas envolvidos celebravam com empenho alguns dos sentidos correntes na construção do imaginário da modernidade: a máquina, a velocidade, o dinamismo, a agressividade, a violência. Articulavam uma postura de combate, com seus manifestos e ações, com a forma de construção estética de suas obras.

Ainda que explicitassem um discurso claro de ruptura, é importante registrar que houve diversas contestações e críticas às contradições do movimento:

$\mathrm{Na}$ exagerada recusa do passado pelos futuristas não se esconde um ponto de vista do operário, mas o niilismo do boêmio. Nós, marxistas, vivemos com as tradições ... . Eis a fonte dos malentendidos que nos separam. O mal não reside na negação, pelo futurismo, das santas tradições da intelligentsia. Reside, ao contrário, no fato de que o futurismo não se sente integrado na tradição revolucionária. (ibidem, p. 110) 
De qualquer forma, trata-se de um movimento de grande importância, impacto e que influenciou outras vanguardas artísticas, antecipando mesmo algumas dimensões que se tornariam mais correntes na arte dos anos seguintes. Como bem resume Micheli:

O futurismo foi um movimento polêmico, de batalha cultural; foi o movimento de uma situação histórica; um amontoado de idéias e de instintos, dentro do qual, ainda que não distintamente, exprimiam-se algumas exigências reais da nova época: a necessidade de ser moderno, de aprender a verdade de uma vida transformada pela era da técnica, a necessidade de encontrar uma expressão adequada aos tempos da revolução industrial. (2004, p. 212)

A prática esportiva foi uma temática constante na obra de muitos futuristas, inclusive na produção do pintor e escultor Umberto Boccioni, um dos mais destacados do Futurismo, autor de alguns dos manifestos do movimento ${ }^{2}$. Para Micheli, ele é: "o representante mais típico e mais dotado do movimento, a personalidade mais conspícua. Do emaranhado das contradições futuristas, ele conseguiu retirar um sentido, uma visão vital" (ibidem, p. 225).

Uma das marcas das obras de Boccioni (tanto das pinturas quanto das esculturas) é a busca de expressar a sensação dinâmica, algo que se tornou ainda mais claro após seu encontro com os cubistas, entre eles Pablo Picasso. Aliás, isso foi fundamental para todo o Futurismo: percebe-se uma clara influência do movimento francês, mas também muitas divergências. Boccioni (2004) situa as propostas dos italianos, do ponto de vista estético, como avanços que partiram tanto dos impressionistas quanto dos cubistas.

Para atingir seu intuito, Boccioni trabalhava a idéia de movimento relativo por meio de uma tensão constante entre forma e espaço, com linhas de força que se aglutinam, notadamente no sentido diagonal, ainda que decomponham a figura. Garantia assim a idéia de uma energia constante que percorre a obra. Além disso, o uso de cores fortes acentua tal impressão. Dinamismo, decomposição, penetração e simultaneidade podem bem resumir as características buscadas pelo artista e pelos futuristas em geral:

Concebimos el objeto como un núcleo (construcción centrípeta) del que parten las fuerzas (líneas-formas-fuerzas) que lo definen en el ambiente (construcción centrípeta) y determinan su carácter essencial. De esta manera creamos una nueva concepción del objeto: el objeto-ambiente, concebido como una nueva unidad indivisible. (2004, p. 63)

A captação da dinâmica do corpo humano foi uma de suas buscas constantes. Em suas obras vemos tanto a representação da movimentação corpórea cotidiana quanto 
a de atividades que pudessem expressar privilegiadamente o movimento humano. Aí encontramos uma primeira e grande aproximação com o esporte enquanto tema de seus quadros e esculturas.

Mas há outra dimensão também muito relevante que o aproxima da prática esportiva: o exaltar do controle sobre a natureza, do homem que supera e até submete os limites naturais. As palavras de Boccioni são explícitas:

Creer que la naturaleza se encuentra donde existe el desorden, la incomodidad, lo caótico (lo "natural" como dicen las almas agrestes) y sobre todo donde falta la mano del hombre, es un error lamentable. Los futuristas detestamos lo campestre, la paz del bosque, el murmullo del arroyo ... Preferimos al hombre transtornado por la pasión o la locura del genio, las grandes barriadas populares, los ruidos metálicos, el rugido de la muchedumbre. Las pistas, las competiciones atléticas, las Carreras nos exaltan! La meta es para nosotros el maravilloso símbolo de la modernidad! (ibidem, p. 17)

Seu interesse denotado pelo corpo em movimento o levou a compor, por exemplo, Músculos em velocidade (1913, tinta e guache sobre papel), Dinamismo muscular (1913, tinta sobre papel) e Dinamismo muscular (1913, pastel sobre papel), entre outras. Suas obras em que o esporte é diretamente representado serão comentadas mais à frente neste estudo.

Ainda que relevante o interesse de um dos maiores expoentes do Futurismo pelo esporte, veremos que não se trata de algo isolado, mas de um dos indicadores da articulação entre estética e política no âmbito de um importante movimento de vanguarda. Aprofundemos tal discussão a partir de alguns dos princípios-chave que permeavam as propostas e ações dos futuristas.

\section{Movimento e velocidade}

Já no manifesto de fundação (1909) ${ }^{3}$ Marinetti afirmara: "Nós tencionamos exaltar a ação agressiva, uma insônia febril, o passo do atleta, o salto mortal, o soco e a bofetada". A figura do esportista e imagens comuns ao esporte são utilizadas para estabelecer um contraponto à imobilidade que, segundo o autor, caracterizaria a arte naquele instante.

Essa idéia é mais à frente reforçada: "Nós afirmamos que a magnificência do mundo se enriqueceu de uma nova beleza: a beleza da velocidade. Um carro de corrida cujo capô é adornado de grossos tubos, qual serpentes de hálito explosivo ... é mais belo que a Vitória de Samotrácia". Uma prática esportiva, o automobilismo, é apresentada 
como esteticamente superior, ou pelo menos mais adequada a uma nova sensibilidade, a um monumento símbolo da tradição artística.

Considerando as proposições e intencionalidades do movimento futurista, não surpreende a referência ao automobilismo, que se tornara uma febre na Europa das primeiras décadas do século XX. Dividindo com o ciclismo a preferência esportiva popular em muitos países, este esporte era relacionado às idéias de aventura, superação, progresso e rapidez; na ocasião, os automóveis já atingiam a velocidade de 100 $\mathrm{km} / \mathrm{hora}$.

De acordo com Micheli, o primeiro manifesto, ao citar tão explicitamente as novas máquinas, estabelece um "decreto de morte da mitologia passada, em favor de uma nova mitologia: o automóvel, ídolo luzidio, troante, utilitário. Como é possível, na era do automóvel, continuar a escrever, a pintar, a construir, a fazer música como na época das diligências e do artesanato?" (2004, p. 214). Esses "fascinantes inventos modernos", na visão dos futuristas, eram a expressão de uma nova sensibilidade a qual os artistas não poderiam negar, não poderiam deixar passar incólume, deveriam incorporar e celebrar.

O próprio Marinetti constantemente se exibia em seu automóvel e inseria imagens dessas máquinas em sua produção. Um exemplo claro dessa forte relação com os sentidos do automobilismo pode ser visto em sua obra ${ }^{4}$ Velocidade elegante palavras em liberdade (primeiro recorde) (1918, colagem e tinta sobre papel): carros de corrida desenhados por todo o quadro; no campo superior direito, os automóveis seguem setas que, tendo a palavra "recorde" como pano de fundo, levam à palavra "pole"; na obra, não com o mesmo destaque, vemos ainda trens e aviões, reforçando o sentido de celebração da velocidade.

Por seu caráter de comparação e por demonstrar que certas dimensões já eram consideradas por alguns futuristas mesmo antes do manifesto, destacamos a gravura Automóvel e a caça da raposa (1904), de Boccioni. Na obra, que já apresenta algumas características que futuramente serão adotadas pelo artista, os cavalos, símbolos de poder e da nova excitabilidade urbana no século XIX, tão representados no âmbito do impressionismo (notadamente na obra de Edgar Degas), têm que sair da estrada para dar passagem a velozes carros. Diferenciam-se claramente as roupas dos cavaleiros que praticam a tradicional caça às raposas (com seus cães que fogem assustados com a aproximação do automóvel) daquelas usadas pelos personagens que conduzem os 
veículos, uma forma mais leve de se vestir. As expressões são contrastantes: o olhar irônico dos "modernos", a preocupação estampada na face dos que seguem a tradição.

As opções estéticas reforçam esses sentidos. O uso das linhas de força diagonais ajuda a enfatizar a idéia de movimento dos carros, criando um contraste com o imobilismo dos cavalos. A utilização de uma técnica de reprodução como a gravura, que avançara muito nas últimas décadas do século XIX, em decorrência do avanço tecnológico, aproxima a obra de um pôster, já na ocasião comumente utilizado para a difusão de produtos da modernidade (Verhagen, 2001). Perspectivas semelhantes são trabalhadas em outras sete obras, não surpreendentemente hoje pertencentes ao Automóvel Clube da Itália.

Vale lembrar que essas obras são produzidas em um momento em que se observa um grande crescimento da popularidade das corridas de automóveis na Itália, cujas primeiras edições foram realizadas em 1895. É também um instante importante no desenvolvimento da indústria automobilista, antecipando o "culto" à escuderia Ferrari, que futuramente extrapolaria as fronteiras italianas. Aliás, Boccioni se inspirara nos modelos Fiat para a composição de suas gravuras.

As novas invenções fascinaram e chamaram muito a atenção dos futuristas: além do automóvel, o trem, a bicicleta, o avião. A tecnologia e a velocidade os atraíam:

Es decir, se trata de encontrar una forma que sea la expresión de este nuevo absoluto: la velocidad, insoslayable para un auténtico temperamento moderno. Se trata de estudiar los aspectos que ha adoptado la vida en la velocidad y en la conseguiente simultaneidad. (Boccioni, 2004, p. 102)

Dado nosso interesse pela prática esportiva, vamos dedicar maior atenção ao ciclismo. Os velocípedes, primórdios de nossas bicicletas, foram inventados, em 1863, pelos irmãos Pierre e Ernest Michaud, logo se tornando uma forma de diversão apreciada pelas elites, um sinal de status e distinção. No final do século XIX as bicicletas começam a ganhar a forma atual e são organizadas as primeiras competições.

A bicicleta deve ser encarada como um invento-chave da modernidade, tanto por ampliar as possibilidades de lazer (seja para passeio ou para a prática de um esporte de competição, seja por estar articulada com a idéia de contemplação), quanto porque foi útil para a produção e para o mundo do trabalho (Weber, 1988).

$\mathrm{Na}$ época dos futuristas, o ciclismo já gozava de grande popularidade em muitos países da Europa, notadamente na França e Itália. Sua relação com este artefato era de tal natureza que muitos deles (inclusive Boccioni e Marinetti) se alistaram, durante a $1^{\text {a }}$ 
Grande Guerra, no Batalhão Ciclista de Voluntários Lombardos, chegando a entrar em combate, alguns até mesmo vindo a falecer durante o conflito bélico (caso de Boccioni).

Como símbolo da modernidade, da velocidade, do progresso, da ousadia, a bicicleta e o ciclismo estiveram bastante representados nas obras dos futuristas, com destaque para as de Boccioni. A lista é grande, portanto citamos apenas alguns exemplos: Dinamismo de um ciclista (1913, têmpera e tinta sobre papel), Ciclista (1913, óleo sobre tela), Forças dinâmicas de um ciclista (1914, litogravura) ${ }^{5}$.

O interesse do artista pelo corpo dos esportistas e pela captação da idéia de movimento das bicicletas o levou a experimentar diferentes técnicas de representação, algo típico em sua obra. O ciclista é quase uma sombra, um espectro em velocidade. Não se pode ver sua face, mas sua posição corporal, as costas curvadas e o rosto vislumbrando o horizonte, típica dos praticantes deste esporte, o aproxima de um combatente em situação de ataque. A falta de outras referências no quadro (é comum que nem sequer haja algo mais representado) faz parecer que os atletas estão voando, aproximando essas obras daquelas em que a aviação está presente, uma temática muito comum entre os futuristas.

Esse interesse se extrapolava para a motocicleta, praticamente uma bicicleta motorizada. Ela esteve representada, por exemplo, por Gerardo Dottori, em Motociclistas (1914, óleo sobre tela), e por Giacomo Balla, em Velocidade de uma motocicleta (1913, óleo sobre tela). Nessa obra, Balla exercita sua idéia de expressar a simultaneidade, exibindo uma série de planos que praticamente não permitem o vislumbrar do condutor: ondas, no sentido da direita para esquerda, representando o deslocamento da moto no espaço, misturam-se a espirais que, em sentido contrário, representam as rodas do veículo, dando ao quadro um incrível aspecto de movimento e velocidade.

Para concluir esse item, devemos ainda destacar a relação dos futuristas com a fotografia e com a arte cinematográfica recém-nascida. O Futurismo também deve ser entendido no âmbito de uma série de iniciativas que buscavam captar adequadamente a nova movimentação da sociedade, algo que se exponenciara no decorrer do século $\mathrm{XIX}^{6}$. Aí está também uma das razões do seu fascínio pelo cinema: a possibilidade técnica de captura, manipulação e exibição de imagens em movimento (como, aliás, também, sob outros parâmetros, o era o esporte, a projetar corpos dinâmicos nas quadras, estádios e piscinas). 
Para expressar melhor a sensação de movimento, alguns artistas faziam uso de seqüências dinâmicas e simultâneas, claramente um diálogo com as cronofotografias de Etienne-Jules Marey e as propostas de Jacques Henri Lartugue. Um exemplo pioneiro de obra nesse sentido é Dinamismo de um cão com coleira, de Giacomo Balla (1915, óleo sobre tela). Carlos Carrá assim tentava traduzir essa perspectiva: "Um caballo corriendo no tiene cuatro patas, sino veinte, y sus movimientos son triangulares" (apud Martin, 2005, p.15).

Os artistas ligados ao movimento produziram fotografias artísticas e filmes, sendo o mais conhecido Vida Futurista (1916), dirigido por Arnaldo Ginna. Nessa película simula-se, de forma desconexa e com tons surreais, o que deveria ser o cotidiano na compreensão do Futurismo. Entre seus oito episódios, um deles era denominado "Ginástica matinal”, cuja descrição, de acordo com Marinetti (apud Tisdall e Bozzolla, 2003, p. 147), é: “Ginástica matinal - esgrima, boxe - luta de espada entre Marinetti e Remo Chiti - discussão sobre luvas de boxe entre Marinetti e Ungari. Café da manhã futurista". A prática esportiva era assim apresentada como um dos hábitos cotidianos adequados por aqueles que propunham uma nova forma de vida em sociedade.

Já se argumentou em outro estudo que as relações entre cinema e esporte são uma expressão típica da modernidade (Melo, 2006). A presença de cenas esportivas em um filme experimental deste movimento de vanguarda somente reforça nossa idéia de que havia um sensível grau de relacionamento entre a prática esportiva e o Futurismo. Em geral, os novos espetáculos públicos lhes interessavam; e desse quadro fortemente fazia parte o ciclismo, o automobilismo, o futebol, o boxe, entre outros.

\section{Luta e Guerra}

Voltemos ao primeiro manifesto (1909). Afirma Marinetti: "Não há beleza senão na luta. Nenhum trabalho sem caráter agressivo pode ser uma obra-prima". Ainda mais: "Glorificamos a guerra - a única higiene do mundo - o militarismo, o patriotismo". E por fim: "Nós cantaremos as grandes multidões entusiasmadas pelo trabalho, pelo prazer e pela insurreição; cantaremos as ondas multicolores e polifônicas da revolução nas capitais modernas"7.

Que relação poderíamos estabelecer entre tais afirmações de Marinetti e o esporte? Basta um olhar nas obras dos futuristas para identificarmos que a prática 
esportiva muitas vezes foi representada com sentidos semelhantes a essas propostas expressas no primeiro manifesto.

Não surpreende, aliás, que o futebol tenha merecido tanta atenção. Desde os momentos iniciais do Futurismo chamava a atenção dos artistas o caráter de disputa, o grande envolvimento popular, o mosaico de imagens e cores, a enorme movimentação física, o sentido patriótico que marcavam a prática do velho esporte bretão naquele momento.

Destacamos, desse instante, a obra Dimensões de um jogador de futebol (1913, óleo sobre tela), de Boccioni. Nesse quadro, a representação do jogador serve bem ao seu intuito de captar o movimento, mas também para celebrar um novo herói, que encara o público em meio a um frenesi de cores e planos.

Esta é considerada uma de suas principais obras, uma daquelas onde alcançou o mais alto grau de diálogo com as propostas do movimento ${ }^{8}$. Ao redor do atleta é central a construção de uma idéia de agressividade e arrogância. Amplia-se significativamente o papel concebido para o esportista no contexto da sociedade daquele momento 9 .

É importante considerar o contexto em que tal esporte se inseria na Itália da década de 1930 para entender sua representação pelos futuristas da segunda geração. No âmbito dos projetos de Mussolini, como metáfora da guerra e ferramenta de construção identitária e patriótica, o futebol ocupou lugar de destaque. É já conhecido o grande investimento governamental (sempre cercado de grande pressão por resultados) realizado nas equipes nacionais (Agostino, 2002). Lembremos que a seleção italiana sagrou-se inclusive campeã das Copas do Mundo de 1934 (organizada pelo próprio país) e de 1938.

A dimensão de luta fica, por exemplo, clara em Partida de futebol (1928, óleo sobre tela), de Gerardo Dottori, um dos principais representantes do movimento em sua segunda fase. Na obra, as diversas espirais garantem a idéia de movimento e linhas diagonais simultaneamente parecem tanto iluminar os atletas, os eleitos, quanto situá-los quase como seres superiores à disputa do objetivo da prática: a bola. Os diversos planos e o uso de cores é típico das composições do movimento. Essas mesmas dimensões são ainda claramente percebidas em Calciatore (Giulio D'Anna, 1930), que retrata um jogador de futebol como um herói, fazendo uma clara alusão e distendendo os formatos tradicionais de representação mítica; bem como em Futebolistas (1934), do mesmo D’Anna, em que se destaca o embate físico entre os atletas. 
Para falar um pouco mais do forte relacionamento entre Futurismo e esporte no âmbito do fascismo, lembremos que no pós-1 ${ }^{a}$ Guerra, Marinetti, já próximo de Mussolini, que fora expulso do Partido Socialista, esteve envolvido com a fundação do Partido Político Futurista. No programa partidário, denominado "Nacionalismo Revolucionário", se afirmava que "a ginástica, o esporte e a instrução militar" deveriam ser obrigatórios e praticados ao ar livre (Humpheys, 2000, p. 70). Nesse momento posterior do movimento permanecerá forte a presença do esporte nas obras. Mesmo que com diferentes ênfases, com algumas dimensões até mais fortalecidas do que no instante anterior, a prática esportiva seguirá sendo importante referência para esse e para outros movimentos futuros ${ }^{10}$.

O esporte e as atividades físicas, com sentido de luta, apareceram explicitamente em outros manifestos do movimento. Em 1913, Marinetti lançou "Destruição da sintaxe - imaginação sem limites - palavras em liberdade", onde fala do aspecto visual de "atletas japoneses e boxeadores americanos" e apresenta como um dos parâmetros a serem seguidos pelos futuristas "a paixão, arte e idealismo do esporte. A idéia e amor ao recorde". Esse mesmo autor, ainda em 1913, em "Programa político do Futurismo", também previa a necessidade de "vitória da ginástica sobre os livros" ". Uma vez mais vemos a prática esportiva sendo utilizada para estabelecer o contraponto à idéia de tradição, que segundo os futuristas deveria ser combatida para faz emergir uma nova arte antenada como a nova sensibilidade da modernidade, bem expressa, segundo a relação estabelecida, pelo espetáculo esportivo.

Explicitamente, percebe-se essa celebração em três obras da segunda fase do movimento: Gare d'atletica (Vittorio Corona, 1926, óleo sobre tela), um mosaico da movimentação dos corpos nas diversas modalidades do atletismo; Atleta alla sbarra (Antonio Marasco, 1929, têmpera e aquarela sobre cartão), certamente uma das mais belas exaltações do significado do atleta no estilo dos futuristas; e Olimpiadi di Paris (Arturo Ciacelli, 1924, óleo sobre tela), que celebrava, por meio da representação dos arcos olímpicos, esse grande evento do esporte mundial. Aliás, vale destacar, esse artista foi convidado para confeccionar os cartazes dos Jogos Olímpicos de Berlim (1936), conhecidos como “Jogos de Hitler" (Holmes, 1971).

Vale ainda comentar que esportes de luta, como o boxe, prática também popular na Itália ${ }^{12}$, foram retratados por artistas futuristas, como em Dinamismo de um corpo humano: boxeador (1913, tinta sobre papel), de Boccioni. 


\section{Uma obra síntese}

Para concluir este item, vale comentar e destacar a obra de Carlo Carrá, Manifestação Intervencionista (1914, colagem sobre cartão). Esse mesmo artista, em seu manifesto "A pintura de sons, barulhos e cheiros" $(1913)^{13}$, já sugerira que o esporte deveria ser predominantemente representado em vermelho. Carrá segue seu próprio conselho em O cavaleiro vermelho (1913, óleo sobre tela), e poucas não foram as vezes, na obra de outros futuristas, em que a cor foi utilizada para representar elementos da prática esportiva.

Curioso é também, do mesmo Carrá, Mulheres nadadoras (1910, óleo sobre tela), um dos primeiros quadros futuristas. A obra era uma clara referência ao poeta futurista Libero Altomare, que fazia uma relação entre a natação e o estado da mente (Tisdall, Bozzola, 2003). Contudo, mais do que a referência literal em obras, é interessante destacar o sentido de excitabilidade proposto por Carrá, expressando sua compreensão sobre a presença da prática na sociedade de seu tempo.

Ainda que Carrá já estivesse se afastando das idéias de Marinetti, algo que se tornaria mais claro nos anos seguintes, notadamente depois de seu encontro com De Chirico, no ano de 1914 deixa-se contagiar pelas idéias de patriotismo no cenário tenso da véspera do grande conflito bélico mundial. Esse sentido impregna Manifestação Intervencionista: "Fiel à sua idéia anterior de pintar ruídos, a 'abstração plástica do tumulto civil' de Carrá, como ele mesmo definiu essa peça, celebra a Itália, seus aviadores, os ruídos da guerra, Marinetti e outros heróis do movimento moderno" (Humphreys, 2000, p. 67).

Manifestação Intervencionista foi publicada na revista Lacerba, órgão de difusão do Futurismo, com o título de Festa Patriótica. Tratava-se de um claro diálogo com as propostas cubistas de Picasso, já adequado às características específicas do movimento. Desaparece a figura e emerge a representação abstrata do tumulto e do caos urbano. $\mathrm{O}$ quadro é composto por palavras que fazem referência às novas dimensões da modernidade, apresentadas na forma de caleidoscópio, fazendo analogia ao turbilhão de novidades que assolava a sociedade. Nesse contexto, a palavra "sports", colocada ao centro, com destaque, nos relembra tanto o papel que tal manifestação já ocupava no contexto social (sua adequação aos "novos tempos"), quanto sua ligação com as propostas do grupo. 
Parece que temos claros indícios para argumentar que houve um profundo diálogo entre o esporte e o Futurismo italiano. Consideremos que este movimento, de diferentes formas e com diversas recepções, serviu de inspiração para artistas de outros países. De certa maneira, percebe-se essa influência no Dadaísmo e em certos momentos da trajetória de Marcel Duchamp e Robert Delaunay. Mas é certamente na Rússia e na Inglaterra que tal relação fica mais clara. Nesses casos, seria possível identificar algum grau de relacionamento com o esporte?

\section{O Futurismo em outros países: a presença do esporte}

\section{O Futurismo russo}

Uma das mais fortes recepções das propostas dos italianos pode ser observada na Rússia, onde inclusive o manifesto de 1909 fora publicado e se sistematizou um movimento denominado Futurismo Russo. Ao comentar a origens da performance naquele país, afirma RoseLee Goldenberg: "o futurismo italiano, estrangeiro o bastante para ser suspeito, porém mais aceitável por fazer eco a esse abandono das velhas formas de arte, foi reinterpretado no contexto russo, proporcionando uma arma que podia ser usada contra toda arte do passado" (2006, p. 24).

Em São Petersburgo e principalmente em Moscou várias foram as iniciativas (exposições, performances, eventos diversos) relacionadas ao Futurismo, destacando-se os nomes de Vladimir Maiakovski, Natalia Goncharova e Kasimir Malevich, entre outros, como expoentes. Majoritariamente, as aproximações com a prática esportiva são tênues, ainda que certas iniciativas desenvolvidas, mais comuns já no âmbito do Construtivismo, estabeleçam algum grau de relação, como as preocupações com o corpo no teatro e os estudos de Meyerhold sobre biomecânica.

O esporte esteve presente em algumas obras do movimento. Goncharova, por exemplo, produziu, em 1913, O ciclista (óleo sobre tela), praticamente uma reprodução de um quadro do Futurismo italiano. Mas é mesmo na produção de Malevich, um dos pioneiros da arte abstrata, que encontramos o maior e mais importante número de referências à prática esportiva.

Malevich, em 1915, lançou as bases do Suprematismo, propondo a quebra definitiva da idéia de figuração, de forma que a obra pudesse explicitar profundamente as sensações internas do artista. Curiosamente um dos primeiros quadros em que 
procurou aplicar suas propostas foi Suprematismo: realismo pictórico de um jogador de futebol (1915, óleo sobre tela). Sobre a obra, afirma Fer:

Em 1915, interpretar o seu Suprematismo: realismo pictórico de um jogador de futebol como arte significava reconhecer os interesses da arte moderna e o que estes vieram a acarretar - a saber, que uma pintura abstrata com o subtítulo de "jogador de futebol" não precisa retratar um futebolista, nem parecer uma figura humana, nem mesmo referir-se esquematicamente a uma figura em movimento, como havia feito o quadro de Boccioni. (1998, p. 31)

Malevich pretendia contestar o modelo de representação dos futuristas, mas nessa obra de transição ainda nomeou o objeto, fez referência a uma forma definida, citou um esporte. Por que logo o futebol? Talvez algum indício possa ser encontrado na fala de Fer:

O quadro de Malevich é feito de formas geométricas coloridas sobre um fundo branco e o espectador não é convidado a "preencher" as partes vazias para compensar as ausências imaginando uma espécie diferente de quadro, mas sim a reconhecer a diferença entre este e outros tipos de representação - a perceber a distância percorrida pelo artista, em vez de refazer seus passos do artista de volta ao motivo original. O significado do quadro de Malevich, como em seu Quadrado Preto, não é garantido por retratar objetos no mundo, ou por uma semelhança qualquer. Não há sentido em procurar um conteúdo figurativo nesta obra do mesmo modo como um connoisseur do século XVIII procura o conteúdo do vazio negro emoldurado que o intriga, numa sátira ao gosto setecentista por turvas cenas noturnas. (1998, p. 31)

Já que sua obra tinha mais informações sobre o que não deveria ser uma pintura, talvez Malevich desejasse criar um contraponto entre algo popular e suas provocações para o campo artístico, "confundindo" os que estavam acostumados ao formato tradicional. Ou talvez quisesse fazer chocar a idéia de algo bem movimentado com um quadro em que essa sensação não fica tão clara. Ou ainda para trazer uma temática mais afeita ao homem comum para o ainda sacralizado mundo da arte (segundo ele pela própria idéia de figura); uma provocação com o campo. É possível que buscasse fazer conexões entre a expressão de sensações profundas com o que era ocasionado pelo espetáculo esportivo. Talvez estivesse interessado no aspecto plástico do futebol. Ou nenhuma das alternativas acima.

Essas assertivas não passam de suposições. Devemos considerar sua ligação com os futuristas (tanto o compartilhar quanto o distanciamento de alguns de seus pressupostos e temáticas), bem como que o artista também se interessava pela noção de dinâmica, apenas não a representando com movimentos rápidos, mas fluxos de sensações que devem nascer do íntimo do pintor, idéia construída a partir de outra concepção de ritmo. De qualquer forma é digna de nota a presença do esporte nessa importante obra. 
Malevich esteve também envolvido com as iniciativas de desenvolvimento de uma arte adequada ao novo regime socialista, nos primeiros anos pós-Revolução Russa, no momento em que Lênin estava na direção. Com a ascensão de Stalin, em certa medida dialogando com o realismo socialista (ainda que dele discordasse), pode-se observar em sua produção um retorno à idéia de representação. Nesse período, no que se refere ao esporte, pintou ainda Suprematismo. Contorno de Sportsmen (1928, óleo sobre tela) e Homem Correndo (1932, óleo sobre tela), obras que ainda demonstravam alguma influência de sua fase áurea, mas que já não expressavam os seus princípios fundamentais originais.

Como se pode ver, a trajetória de Malevich tem relação com as mudanças de rumo na política soviética, algo que influenciou a arte em geral daquele país. A própria apreensão inicial do Futurismo fora bastante alterada com os desdobramentos da Revolução Russa. Trotski contestava as proposições futuristas:

\footnotetext{
Devemos rejeitar tais pretensões. Isso não significa desprezo pelas obras dos futuristas. Elas constituem marcos necessários à formação de uma nova e grande literatura, em cuja evolução compõe apenas um episódio significativo. Basta, para se convencer disso, abordar a questão mais concretamente, no plano histórico ... . Ainda faltam às massas, evidentemente, cultura e formação estética às quais elas só lentamente se elevarão. Esta representa apenas uma das causas pelas quais o futurismo lhes permanece inacessível. (2007, p. 128)
}

O próprio Maiakovski se esmerava em afirmar que as diferenças entre russos e italianos eram muitas, ainda que existissem pontos em comum. Todavia o maior número de contestações parte mesmo de outro movimento que também estabelecera muitos relacionamentos com o Futurismo: o Vorticismo da Grã-Bretanha: "A reação dos jovens artistas londrinos ao Futurismo levou à criação do movimento vorticista que, embora muito influenciado por diversos aspectos das idéias e das práticas dos grupos italianos, manteve uma independência crítica e convicta" (Humphreys, 2000, p. 49).

\section{O Vorticismo}

Há diferenças marcantes entre o Futurismo e o Vorticismo: os ingleses, embora buscassem também captar a idéia de dinamismo, opunham-se ao fascínio dos italianos pela velocidade. Ao contrário destes, que exaltavam e celebravam o espírito de seu tempo; aqueles, ainda que também engajados na contemporaneidade, preconizavam certo distanciamento, inclusive no que se refere à postura política, levantando a 
necessidade de garantir autonomia para a arte. Enfim: "enquanto os futuristas italianos enxergavam na era da máquina augúrios de uma emancipação humana quase selvagem por meio da tecnologia, Hulme e diversos vorticistas viam na maquinaria ... sinais de um modernismo extraordinariamente autoritário" (Humphreys, 2000, p. 57).

No que se refere ao tema deste estudo, encontramos também claras diferenças. Em Blast, jornal ligado ao Vorticismo, constantemente se proferiam ataques aos hábitos e valores da classe média inglesa, entre os quais o costume de fazer esportes. Obviamente que devemos considerar que a prática esportiva exaltada pelos italianos era aquela de caráter popular, enquanto os ingleses atacavam o seu caráter aristocrático, muito forte no país que praticamente dera origem ao esporte em seu sentido moderno ${ }^{14}$. Os vorticistas, inclusive, ironicamente chamavam o Futurismo de "automobilismo". Ainda os afastava do esporte o seu repúdio à idéia de multidão.

Mas o esporte esteve também presente em algumas obras do movimento. David Bomberg, por exemplo, compõe, em 1913, Corridas de Cavalos, em que os personagens são cilindros, quase bonecos de cano em meio a um caos, uma representação muito próxima da idéia futurista de expressar os elementos da obra enquanto máquinas. No ano seguinte, o artista produziu Ju-Jitsu, um óleo sobre tela que, a título de trabalhar o tema "violência", apresenta os lutadores como formas geométricas desordenadas em meio a um mosaico que apresenta certo padrão de regularidade.

Os esportes de luta também foram representados por dois outros artistas vorticistas. Henri Gaudier-Brzeska produziu várias obras ligadas à luta livre. Em 1912 fora contratado para fazer um quadro sobre lutadores e tendo ido a um ginásio acabou se apaixonando pelas qualidades atléticas dos praticantes, o que o levou a compor vários desenhos, pinturas e mesmo esculturas sobre o tema. Já Wyndham Lewis, um dos líderes do Vorticismo, produziu a Boxe em Juan-les-Pins (1929, aquarela, caneta e tinta sobre papel), um belo quadro de uma disputa pugilística. De qualquer maneira, os ingleses não demonstraram com a prática esportiva o mesmo grau de entusiasmo que os italianos.

E no Brasil? Como chegaram as idéias de Marinetti e seus seguidores? Os artistas envolvidos com o Modernismo, notadamente oriundos de São Paulo, em razão de suas ações e de seus intuitos de desenvolver uma arte de vanguarda no país, foram chamados de "futuristas"; contudo, devemos olhar com cuidado a recepção e o diálogo com o movimento italiano. 
O Futurismo paulista

É verdade que o contexto de São Paulo das décadas de 1910 e 1920 apresentava algumas similaridades com o cenário italiano: rápida industrialização, crescente urbanização, conflitos políticos. Algumas das propostas do grupo de artistas brasileiros envolvidos com o Modernismo se aproximavam mesmo das do Futurismo e é inegável que houve contatos, que têm início com Oswald de Andrade, que trouxera da Europa a "novidade", em 1912, e chega até a visita de Marinetti ao Brasil (Fabris, 1994; Brito, 1997). A exposição de Anita Mafalti e mesmo a Semana de Arte Moderna de 1922 têm algum grau de relação com as ações futuristas. As polêmicas, como na Itália, foram muitas.

Mas houve várias divergências dos brasileiros com os projetos de Marinetti e seus seguidores. Em certo sentido, estavam ligadas a efetivas reelaborações nacionais; todavia não devemos deixar de considerar que: "A crítica que os modernistas fazem ao futurismo de Marinetti não prova apenas que sua modernidade era incipiente, mas demonstra sobretudo que não existiam no Brasil as condições necessárias ao pleno desenvolvimento de um projeto moderno" (Fabris, 1994, p. 132).

O uso corrente do termo "futurismo", muito observado na ocasião, tanto com sentido de valorização como de detração, expressou mais o desejo de se sincronizar com a vanguarda européia e à falta de uma compreensão mais profunda acerca do movimento italiano, do que exatamente o seguir das mesmas dimensões; tratou-se de um uso mais instrumental ${ }^{15}$.

O estudo de Fabio Peres (2007) nos mostra que entre os artistas ligados ao Modernismo também o esporte esteve representado. Podemos citar, entre outros: Combate (1927, óleo sobre tela), Tênis (1928, óleo sobre tela), Atletas (década de 1930, óleo sobre tela) e Goleiro (década de 1930, óleo sobre tela), de Vicente Rego Monteiro; Regata (1928, óleo sobre tela), Jogo de futebol em Brodowski (1933, óleo sobre tela), Futebol (1935, óleo sobre tela), Jogando futebol (1939, nanquim) e Futebol (1940, óleo sobre tela), de Cândido Portinari; Futebol (1936, óleo sobre tela), de Francisco Rebolo; Mulher nadando (1930, aquarela e nanquim sobre papel) e Goleiro (década de 1930, óleo sobre tela), de Cícero Dias.

Se é interessante identificar que o esporte começa a ser mais representado nas artes plásticas brasileiras, algo ainda não observado até então, não devemos incorrer no 
equívoco de crer que os sentidos eram os mesmos que levavam a prática esportiva a estar presente na produção dos futuristas. No cenário brasileiro, tal inserção tinha relação com uma maior presença de elementos do cotidiano e da cultura popular nas obras.

De qualquer forma, não é de estranhar tal presença se tivermos em vista o contexto sociocultural. Como bem informa Nicolau Sevcenko:

\footnotetext{
Não causa surpresa, portanto, o fato de que no momento em que alcançou sua fase de crescimento urbano mais acelerado, logo depois da $1^{\text {a }}$ Guerra Mundial, São Paulo tenha experimentado um espantoso boom dos esportes. A cidade toda se transformou num gigantesco estádio polivalente. (1993, p. 83)
}

Aliás, a presença do esporte no cotidiano da cidade de São Paulo já fora sentida em dois filmes lançados na década de 1920. Um deles é Vício e Beleza (1926), dirigido por Antônio Tibiriçá, com argumento de Menotti del Pichia, artista ligado ao Modernismo. A película narra a história de um estudante de medicina, praticante de natação e atletismo, que apregoa as benesses da atividade física para a saúde, em contraponto a outro jovem que freqüenta cabarés e tem uma vida conturbada. No decorrer da trama, são apresentados os problemas ligados a doenças venéreas, ao uso de drogas e à vida desregrada. Com forte caráter moralizador, tal filme foi produzido em um contexto de busca de controle e organização da capital paulista, quando cresciam problemas típicos da rápida urbanização e do inchaço urbano.

Já São Paulo, sinfonia de uma metrópole (1929, Rodolfo Lustig e Adalberto Kemeny) foi inspirada em Berlim, sinfonia de uma metrópole (1927, Walther Ruttmann). Trata-se de um documentário sobre a cidade na transição das décadas de 1920-1930, um panorama do frenesi de uma metrópole e de seus personagens cotidianos. O filme busca capturar a excitabilidade da vida moderna e industrial, exibida de uma maneira esteticamente adequada às novas dimensões culturais em vigor. Nesse cenário, o esporte ocupa espaço relevante.

A presença da prática esportiva tanto em um filme que intenta traçar um panorama dos "novos tempos" quanto nas obras dos modernistas, que de alguma forma estavam buscando captar e/ou antecipar os indícios de uma nova sensibilidade, demonstra o já alto grau de inserção da manifestação na dinâmica social do país, sua importância simbólica, sua articulação com as outras dimensões culturais.

Para encerrar, vale lembrar que um dos responsáveis pelo incentivo financeiro para muitas das ações dos modernistas era a família Prado, notadamente Paulo Prado. A 
mesma família esteve envolvida com as reformas urbanas da capital paulista, já que Antônio Prado, pai de Paulo, ocupara durante muitos anos a função de intendente (prefeito). Outro dos filhos de Antônio, Prado Júnior, foi figura de grande destaque na política e no esporte nacional, como atleta de ciclismo, como presidente de Clube Atlético Paulistano, como presidente do Comitê Olímpico Brasileiro e membro do Comitê Olímpico Internacional. Coincidência? Não creio. É mais provável que seja mais um indício de que estamos falando de sensibilidades em comum em um determinado contexto, algo que envolvia esporte, arte e modernidade.

\section{Conclusão}

Várias são as dimensões que favorecem o diálogo entre esporte e Futurismo. Uma delas é o fato de o espetáculo esportivo se organizar de forma diferenciada da restrita tradição acadêmica; era "o novo", uma manifestação plenamente integrada à cultura de massas que recém se estruturava nos anos iniciais do século XX. Se os futuristas contestavam as bibliotecas, galerias e museus, encontravam em outros espaços, como estádios e quadras, seus locus de celebração de uma nova arte. Adendase a isso o aspecto visual da prática esportiva: dinâmico, veloz, tumultuado, ótimo para ser representado a partir das proposições do grupo.

O movimento futurista era espetacular em seu modus operandis, em sua forma de comunicação: manifestos claramente iconoclastas e exagerados, organização de performances públicas com o intuito de chocar, a própria natureza das obras. Os eventos esportivos, em certo sentido, se aproximam de suas "seratas", onde, ao contrário das exposições de arte tradicionais:

Los artistas organizaban muchas veces con poco margen de tiempo en diversos lugares y cuyos programas incluían puntos variables. Integradas por recitaciones de poemas, manifiestos y números musicales, constituían el marco de una acción artística que buscaba la provocación y el alboroto. (Martin, 2005, p. 9)

RoseLee Goldeberg (2006) situa o Futurismo entre os que pioneiramente deram origem à performance como hoje a conhecemos. Ressaltamos tal dimensão na medida em que as proximidades entre o esporte e a performance são notáveis até mesmo no âmbito do idioma, algo também observável em vários dicionários. Como observa Antonio Herculano Lopes: 
O termo performance há algum tempo é moeda corrente no nosso idioma. Se em princípio era mais identificado com os esportes e as máquinas, com o sentido de "desempenho", mais recentemente passou a circular na área artística, para indicar um ato mais ou menos teatral, com um certo grau de improvisação e de uso do acaso e altas doses do pós-moderno vale-tudo. (2003, p. 5)

Esse mesmo autor demonstra como vários autores percebem proximidades significativas entre o esporte e a performance, como é o caso de Schecner (2003). Na verdade, Lopes demonstra que historicamente é possível argumentar que há um bom grau de relação. As fronteiras são mesmo tênues:

\begin{abstract}
Além disso, mesmo quando a performance possui uma forte dimensão estética, ela não é, necessariamente, arte. Os movimentos de jogadores de basquete são tão belos quanto os de bailarinos, mas o basquete é o esporte e o ballet - arte. Reflita agora sobre a patinação e a patinação artística, que existem em ambos os universos. Decidir o que é arte depende de contexto, circunstância histórica, uso e convenções locais. (2003, p. 31)
\end{abstract}

Aproxima, então, esporte e Futurismo o fascínio pela organização espetacular dessa diversão moderna, sua possibilidade de envolver multidões em torno de uma prática social, algo que por razões diferenciadas também tinha chamado a atenção de outros artistas, como Bertold Brecht (Teixeira, 2003; Melo \& Vaz, 2006).

Outra importante dimensão a ser considerada é a idéia de que os artistas deveriam se assumir enquanto soldados e trabalhadores, o que os aproximavam dos esportistas, eles também encarados como combatentes e operários de uma nova celebração moderna: o esporte entendido como um simulacro da guerra, uma forma de violência controlada, algo eivado de agressividade, além de uma ode ao nacionalismo e patriotismo.

O esportista era o novo herói da modernidade, enquanto não vinha o conflito bélico tão propalado, esperado e requisitado. Era o misto de homem e máquina que poderia ajudar a construir para a civilização a idéia da necessidade de progresso. Devemos lembrar que as noções de desempenho, de recorde e de guerra foram constantes entre os futuristas: "Practicamente todos los artistas futuristas, con la excepción del escritor Aldo Palazzeschi (1885-1974), ensalzaron la guerra y sus consecuencias" (Martin, 2005, p. 80).

O esporte, enfim, uma prática social já de destaque nos primeiros anos do século $\mathrm{XX}$, encontraria ecos e possibilidades de diálogo com as propostas do Futurismo, que celebrava o "hábito da energia", "o movimento agressivo", a "velocidade", o "salto mortal", a "bofetada", "o murro", termos expressos no primeiro manifesto de 1909. 
Somente no impressionismo, por motivos diferenciados, encontramos tamanha relação com o esporte. Se naquele o olhar era desconfiado, entre os futuristas era de elegias e glórias, de entusiasmo e exaltação.

Por compartilharem sensibilidades, a construção de sentidos e significados culturais e a celebração de determinadas imagens em comum, o entendimento das relações entre esporte e Futurismo nos permite lançar mais um olhar que nos possibilita ampliar nossa compreensão sobre a consolidação do ideário e do imaginário da modernidade.

\section{REFERÊNCIAS BIBLIOGRÁFICAS:}

AGOSTINO, G. Vencer ou morrer: futebol, geopolítica e identidade nacional. Rio de Janeiro: Mauad/Faperj, 2002. 271 p.

BOCCIONI, U. Estética y arte futuristas. Barcelona: Quaderns Crema, 2004. 175 p.

BOURDIEU, P. Como é possível ser esportivo? In: . Questões de sociologia.

Rio de Janeiro: Marco Zero, 1983. p.136-63.

BRANCO, C. Os papéis sociais do futebol brasileiro revelados pela música popular (1915-1990). In: SILVA, F. C. T., SANTOS, R. P. Memória social dos esportes. Rio de Janeiro: Maud/Faperj, 2006. p. 187-228.

BRITO, M. S. História do Modernismo brasileiro. Rio de Janeiro: Civilização Brasileira, 1997. 319 p.

BURKE, P. Testemunha ocular: história e imagem. Bauru: Edusc, 2004. 264 p.

CORBIN, A. História dos tempos livres. Lisboa: Teorema, 2001. 514 p.

DEBORD, G. Sociedade do espetáculo. Rio de Janeiro: Contraponto, 1997. 127 p.

FABRIS, A. O Futurismo Paulista. São Paulo: Edusp/Perspectiva, 1994. 296 p.

FER, B. Introdução. In: FRASCINA, F. e colaboradores (org.). Modernidade e modernismo: a pintura francesa no século XIX. São Paulo: Cosac \& Naify, 1998. p.349.

GOLDBERG, R. A arte da performance. São Paulo: Martins Fontes, 2004. 228 p.

GONZÁLEZ, T. A. Introducción del deporte en Espana. Su repercusión en el arte. Madrid: Edilupa, 2003. 123 p.

GRAHAM, G. Filosofia das artes. Lisboa: Edições 70, 1997. 156 p.

GUASTINI, M. A hora futurista que passou. São Paulo: Boitempo, 2006. 239 p. 
GUMBRECHT, H. Elogio de la belleza atlética. Buenos Aires: Katz, 2006. 285 p.

HOLMES, J. Olimpíada -1936 - glória do Reich de Hitler. Rio de Janeiro: Renes, 1971. $65 \mathrm{p}$.

HUITOREL, J-M. La beaute du geste. Paris: Editions du Regard, 2005. 215 p.

HUMPHREYS, R. Futurismo. São Paulo: Cosac \& Naif, 2000. 80 p.

JEU, B. Analyse du Sport. Paris: PUF, 1992. 191 p.

LOPES, A. H. Performance e História. Percevejo, Rio de Janeiro, ano 11, n.12, p.5-24, 2003.

MANNONI, Laurent. A grande arte da luz e da sombra. São Paulo: Senac/Editora Unesp, 2003. 434 p.

MARAÑÓN, C. Fútbol y cine. Madrid: Ocho y medio films de cine, 2005. 337 p.

MARTIN, S. Futurismo. Madrid: Taschen, 2005. 95 p.

MELO, V. A. Cinema e esporte: diálogos. Rio de Janeiro: Aeroplano/Faperj, 2006a, $138 \mathrm{p}$.

MELO, V. A. A presença do esporte e do lazer em obras de arte: uma análise comparada de impressionistas e futuristas. Fênix: Revista de História e Estudos Culturais, Uberlândia, v. 3, ano 3, n. 3, sem página, jul.-set.2006b. Disponível em http://www.revistafenix.pro.br.

MELO, V. A., MONTEIRO, M. B. O esporte no âmbito do Novo Realismo. In: ENCONTRO REGIONAL DE HISTÓRIA/ANPUH-RJ, 12, 2006. Anais... Rio de Janeiro: UFF, 2006, sem página.

MELO, V. A., VAZ, A. F. Cinema, corpo, boxe: suas relações e a construção da masculinidade. Artcultura, Uberlândia, v. 8, n. 12, p.139-60, 2006.

MICELI, S. Imagens negociadas. São Paulo: Cia. Das Letras, 1996. 174 p.

MICHELI, M. As vanguardas artísticas. São Paulo: Martins Fontes, 2004. 251 p.

PERES, F. F. Práticas corporais e as artes plásticas brasileiras: um ensaio sobre o modernismo nas décadas de 20 e 30. Rio de Janeiro, 2007. mimeo.

SCHECNER, R. O que é performance? Percevejo, Rio de Janeiro, ano 11, n. 12, p.25$50,2003$.

SEVCENKO, N. Transformações da linguagem e advento da cultura modernista no Brasil. Estudos Históricos, Rio de Janeiro, v. 6, n. 11, p. 78-88, 1993.

SOARES, L. E. Futebol e teatro: notas para uma análise de estratégias simbólicas. Boletim do Museu Nacional, Rio de Janeiro, n.33, p. 1-23, jun.1979. 
TEIXEIRA, F. N. Prazer e crítica: o conceito de diversão no teatro de Bertold Brecht.

São Paulo: Annablume, 2003, 67 p.

TISDALL, C., BOZZOLLA, A. Futurism. New York: Thames e Hudson, 2003. 216 p.

TROTSKI, L. Literatura e revolução. Rio de Janeiro: Jorge Zahar, 2007. 254 p.

VERHAGEN, M. O cartaz na Paris fim-de-século: “aquela arte volúvel e degenerada".

In: CHARNEY, L., SCHWARTZ, V. (orgs.). O cinema e a invenção da vida moderna.

São Paulo: Cosac \& Naify Edições, 2001. p. 151-86.

WEBER, E. França fin de siecle. São Paulo: Companhia das Letras, 1988. 234 p.

WELSCH, W. Esporte - visto esteticamente e mesmo como arte? Filosofia política, série III, n. 2, p. 142-65, 2001.

MELO,Victor Andrade de. Sport, futurism and modernity. História, São Paulo, v. 26, n. 2, p. 201-225, 2007.

Abstract: This study objective is to discuss the relations between sport and Futurism, one of the noisiest, influential and controversial movements of the European artistic vanguard. We believe that by this study we can discuss about the importance of these social practices (sport and art), considering the dialogues between them, as well as the construction of modernity imaginary in the $20^{\text {th }}$ century first decades. Aiming this objective, we search to dialogue with Peter Burke ideas (2004) about the possibility of building a "cultural history of the image" or a "historical anthropology of the image". We have emphasize masterpieces and manifests analyses of Futurism first phase. We hope that our efforts can contribute to the promotion of a "social archaeology" of the sport, unmasking its presence in the social context.

Keywords: sport; futurism; modernity

Artigo recebido em 08/2007. Aprovado em 11/2007.

\section{NOTAS:}

\footnotetext{
* Professor do Programa de Pós-Graduação em História Comparada/Instituto de Filosofia e Ciências Sociais/Universidade Federal do Rio de Janeiro (UFRJ); Pesquisador do Laboratório de Estudos do Tempo Presente/UFRJ e do Programa Avançado de Cultura Contemporânea/UFRJ. Bolsista de Produtividade em Pesquisa/CNPq. Agradeço aos apoios do CNPq e da Fundação de Amparo à Pesquisa do Estado do Rio de Janeiro pelos auxílios financeiros e bolsas concedidos para esta investigação.

${ }^{1}$ O livro "Literatura e Revolução", do qual retiramos a carta de Gramsci, foi escrito por Trotski entre os anos de 1921-1922. A carta de Gramsci está datada como de 8 de setembro de 1922.

${ }^{2}$ Uma das características do Futurismo é o grande número de manifestos que buscavam apresentar seus princípios e pressupostos, expressão de seu intuito de articular reflexões teóricas com a produção de obras.

${ }^{3}$ Os manifestos foram acessados em: http://www.futurism.org.uk. No caso do primeiro manifesto, os onze pontos estão reproduzidos no livro de Humphreys (2000).
} 


\footnotetext{
${ }^{4} \mathrm{O}$ fato de citarmos algumas obras, o elencar de certos temas na produção artística do movimento, ainda que seja um importante indicador, não deve obliterar nossa compreensão de que o sentido da mobilização de imagens esportivas está para além de sua inserção literal.

${ }^{5}$ Outros exemplos: O ciclista (Gino Severini, 1914, óleo sobre tela, 1914); Ciclista (Gerardo Dottori, 1916, aquarela sobre cartão); Dinamismo. Velocidade + ciclista (Roberto Baldessari, 1915); Ciclista Campeão (Pasqualino Cangiullo, 1917, têmpera sobre cartão); entre outros.

${ }^{6}$ Para maiores informações, ver estudo de Mannoni (2003).

${ }^{7}$ Os manifestos foram acessados em: http://www.futurism.org.uk.

${ }^{8}$ Para maiores informações, ver estudo de Martin (2005).

${ }^{9}$ Boccioni ainda representou este esporte em Dinamismo de um corpo: futebolista (1913, tinta e grafite sobre papel), quando seu interesse parece se centrar nas movimentações corporais do jogador por ocasião de um drible.

${ }^{10}$ Podemos, por exemplo, perceber sua notável presença no âmbito do Novo Realismo, da Pop Art e da Nova Figuração Brasileira (Melo \& Monteiro, 2006).

${ }^{11}$ Os manifestos foram acessados em: http://www.futurism.org.uk.

${ }^{12}$ Para uma discussão sobre a grande presença do boxe em obras de arte, ver estudo de Melo e Vaz (2006).

${ }_{13}^{13}$ Os manifestos foram acessados em: http://www.futurism.org.uk.

${ }_{15}^{14}$ Para maiores informações, ver estudo de Bourdieu (1983) e Corbin (2001).

${ }^{15}$ Mais informações sobre as polêmicas podem ser obtidas no estudo de Fabris (1994), Brito (1997) e no livro de Guastini (2006), cuja primeira edição é de 1926. Algumas interessantes ponderações sobre o Modernismo podem ser obtidas no estudo de Miceli (1996).
} 